\title{
Effect of Submergence Stress on Physiological Indices and Yield of Rice (Oryza sativa L.) Genotypes
}

\author{
Ashish Kumar*, Shambhoo Prasad,Vishwash Kumar Mishra, Rahul Kumar, \\ Jaswant Singh, Ram milan and Adesh Kumar
}

Department of Plant Molecular Biology and Genetic Engineering, Acharya Narendra Deva University of Agriculture \& Technology Kumarganj, Ayodhya-224229 (U.P.) India

\begin{tabular}{l} 
Ke y w o r d s \\
$\begin{array}{l}\text { Rice, Submergence } \\
\text { stress, Catalase, } \\
\text { Peroxidase, Shoot } \\
\text { elongation }\end{array}$ \\
\hline Article Info \\
\hline $\begin{array}{l}\text { Accepted: } \\
\text { 15 December } 2019 \\
\text { Available Online: } \\
\text { 20 January } 2020\end{array}$ \\
\hline
\end{tabular}

\section{Introduction}

Rice is the world's single most important food crops and primary food source for one third of the world population. Within the country, rice occupies $1 / 3$ of the total cropped area, contributes about 40 to $43 \%$ of total food grain production and continues to play a key role in the national food and livelihood security system. India rank second among the top most rice producers in the world after China. Rice crops are prone to various types of stresses, both biotic and abiotic. Biotic stresses include insect pests, fungus, bacteria, viruses, and herbicide toxicity Among abiotic stresses, drought, cold, submergence and salinity are also well studied in rice (Ansari et al., 2015).

Submergence and drought are the two most 
prevalent climate disasters that hamper growth and development of all crop plants, causing major yield reduction globally. These two abiotic stresses can completely destroy crop production in extreme conditions, and consequently both of stresses are considered as key determinants of global food security. Moreover, climate change is also projected to undermine global food security (IPCC, 2014).

Submergence is a type of flooding stress and is defined as a condition where the entire plant is fully immersed in water (complete submergence) or at least part of the shoot terminal is maintained above the water surface (partial submergence). About $8.0 \mathrm{~m}$ hectare of rice area is flood/submergence prone in India that constitutes around $35 \%$ of the total rice area categorized under rain fed lowland and flood prone ecology (Reddy et al., 2013).

Submergence generally occurs at vegetative stage while drought at reproductive stage in frequent manners in life span of the crop. During submergence, tolerant rice plants exhibit inhibition of shoot elongation, retain chlorophyll in leaf tissues and maintain viability. If rice is submerged under water more than a few days, gradual loss of oxygen leads to withering and death due to the effect on respiration and photosynthesis. Water stress may effect on the plants anatomy, morphology, physiology and biochemistry and influence on almost all of their growth and development aspects.

It creates the damages to plant as consequences of; slow rates of gas exchange, severe shading by turbid water, mechanical damage due to strong flow rates and solute carrying capacity of flooded water (Michael and Phool, 2001). Rice and other aquatic plants tend to elongate when completely submerged and try to emerge on the surface of water through shoot elongation at the expense of reserve substrates used in energy production. In flash flood rice growing areas of eastern India, where submergence occurs only for 1 - 2 weeks, excess shoot elongation is eventually harmful resulting in lodging and death of plants when flood water recedes. The impact of these finding is that elongation growth competes with maintenance process or energy and reduces survival during submergence.

Reactive oxygen species including super oxide, hydrogen peroxide, hydroxyl radicals and singlet oxygen are the inevitable by products of cell metabolism when molecular oxygen enters suddenly into the cells after exposure of plants to air during post submergence phase. The elevated levels of these free radicals of oxygen cause membrane damage through lipid peroxidation and protein denaturation if not removed rapidly by oxygen scavenging systems (Ella et al., 2003) though oxygen scavenging systems (AOS) are constitutive, they can show higher activity in response to re-exposure to oxygen after a period of anoxia induced by flooding or submergence.

\section{Materials and Methods}

The experiment was conducted at Student Instructional Farm, submergence tank and net house of N.D. University of Agriculture and Technology, Kumarganj, Ayodhya. (U.P.) during kharif season 2017-18. The geographical situation of Ayodhya district lies between a latitude from $26^{\circ} 47^{\prime \prime}$ north and longitudes of $82^{\circ} 12^{\prime \prime}$ east, an altitude of 113 meters above the mean sea level in the gangtic alluvium soil of Eastern Uttar Pradesh. The material for this study consisted a pot culture experiment was conducted with four rice genotypes viz Swarna Sub1, NDR102, NDR-97. Thirty five days old direct seeded rice was exposed to 11 days complete submergence treatment. $90-100 \mathrm{~cm}$ water 
lavel was maintained in submergence tank during submergence period.

Catalase activity was recorded by the methods of (Sinha et al., 1972). Shoot elongation was recorded by taking length from the base of plant to the panicle. The height submerged plant deducted from the height control plant at the end submergence and considered as shoot elongation. Days to $50 \%$ flowering was recorded when $50 \%$ plants come into an thesis from date of sowing. Grain yield per plant was recorded randomly taking yield five plant average out two one as grain yield per plant $(\mathrm{g})$.

\section{Results and Discussion}

\section{Catalase activity}

The Catalase activity abruptly increased in all rice genotypes after de-submergence. The maximum catalase activity after desubmergence was recorded in Swarna Sub 1 (283.08\%) and NDR-9830102 (204.71\%), while low inNDR-97 (85.64). Nagina-22 failed to survive after desubmergence.

\section{Peroxidase activity}

Peroxidase activity suddenly increased in rice genotypes after desubmergence. The high percent peroxidase activity was estimated in swarna Sub-1 (406.25\%) and NDR-9830102 (408.97\%) while low in NDR-97 (383.95\%). Nagina-22 could not survived after desubmergence. Catalase and peroxidase activity abruptly increased high in tolerant plant over control after desubmergence due to formation of the reactivity oxygen species (ROS) just after desubmergence. The ROS are chemically aggressive species and the attack of free radicals on the polyunsaturated fatty acid components of membrane lipids initiates lipid peroxidation, an autocatalytic process that changes membrane structure and function
(Verma et al., 2003).

\section{Shoot elongation (cm) and survival (\%) of the plant}

Survival of rice plant severally affected after 11 days complete submergence treatment. It is clear from the data that the survival of all the genotypes where affected under submergence condition. But survival of Nagina-22 was badly affected and no plant survived after desubmergence. Maximum survival was recorded in swarna Sub-1 (95.45\%) followed by NDR-9830102 (85\%), NDR-97 (5\%). The elongation of shoot or leaf is primary responses to ethylene entrapped in the growing tissue by the flood water. The hormone is known to act in conjunction with gibberellins and/or with auxin to stimulate cell extension. In stems of deepwaterrice (Kende et al., 1998) and petioles of Rumex palustris (Cox et al., 2003) faster underwater elongation is strongly dependent on a prior degradation of the growth-inhibiting hormone abscisic acid. Leaves of rice seedlings may also respond to a signal other than ethylene. That signal may comprise of accumulated carbon dioxide or partial oxygen shortage since rice coleoptiles elongate faster underwater in response to their collaborative effects as well as to ethylene.

Generally all rice genotypes showed delayed flowering as well as maturity in submergence condition the maximum delays in 50\% flowering and maturity (100\% flowering ) was recorded in NDR-9830102 (9.45\%) while minimum in swarna sub-1 $(9.40 \%)$ in terms of percent increase over control condition

All rice genotypes showed the genetic variability in grain yield per plant under submergence condition. In submergence condition NDR-97 and Nagina-22 showed high reduction percentage $(100 \%)$ and could not produce any yield in comparison to NDR- 
$9830102 \quad(78.36 \%)$ and swarna sub-1 $(77.76 \%)$. Grain yield is directly associated with number of parameters such as tillers, number of panicles, number of grains/plant and test weight. Reduced tillering and grain sterility under submergence are the crucial parameters affecting yield. Under complete submergence, plant received diffused light of low intensity, which might be primary cause of reduction in tiller number (Tanaka et al., 1964)Reduction in tiller number under flooding could also be attributed to the differential sensitivity of tolerant and intolerant genotypes to ethylene, which could trigger senescence of developing tiller primordial.

Fig.1 Effect of submergence treatment on catalase activity (unit $\mathrm{g}^{-1}$ fresh wt.) of rice genotypes and mapping population

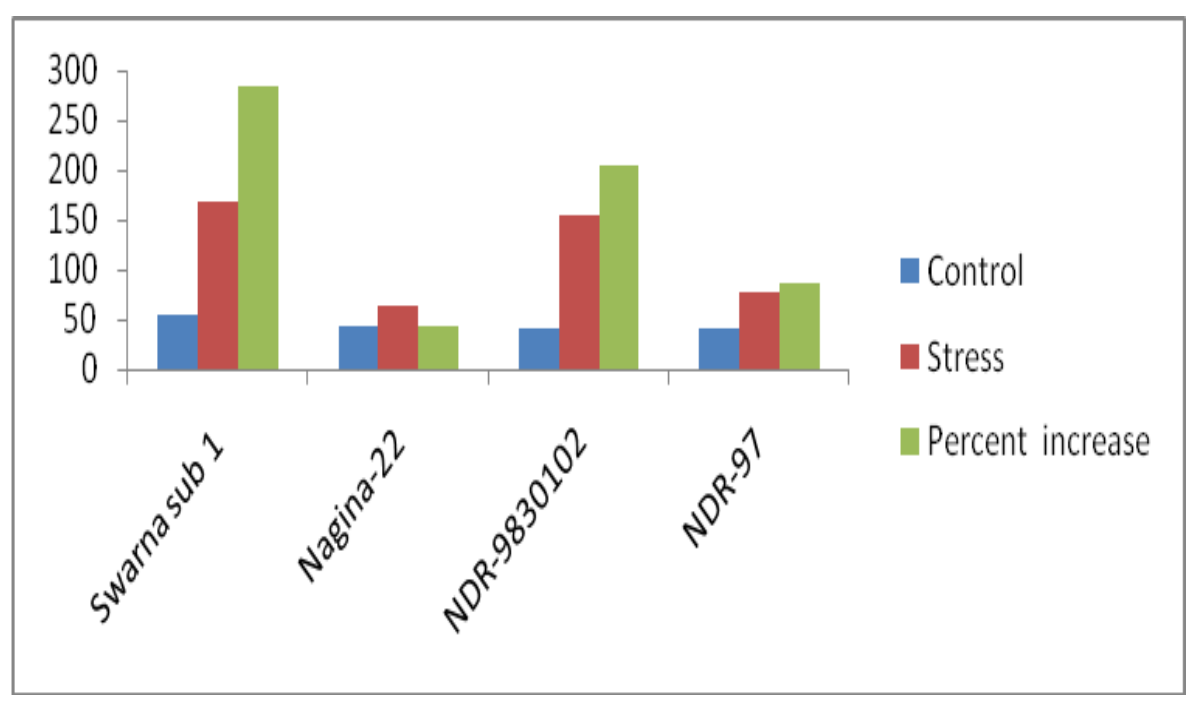

Fig.2 Effect of submergence treatment on peroxidase activity (unit $\mathrm{g}^{-1}$ fresh wt. $\mathrm{min}^{-1}$ ) of rice genotypes and mapping population

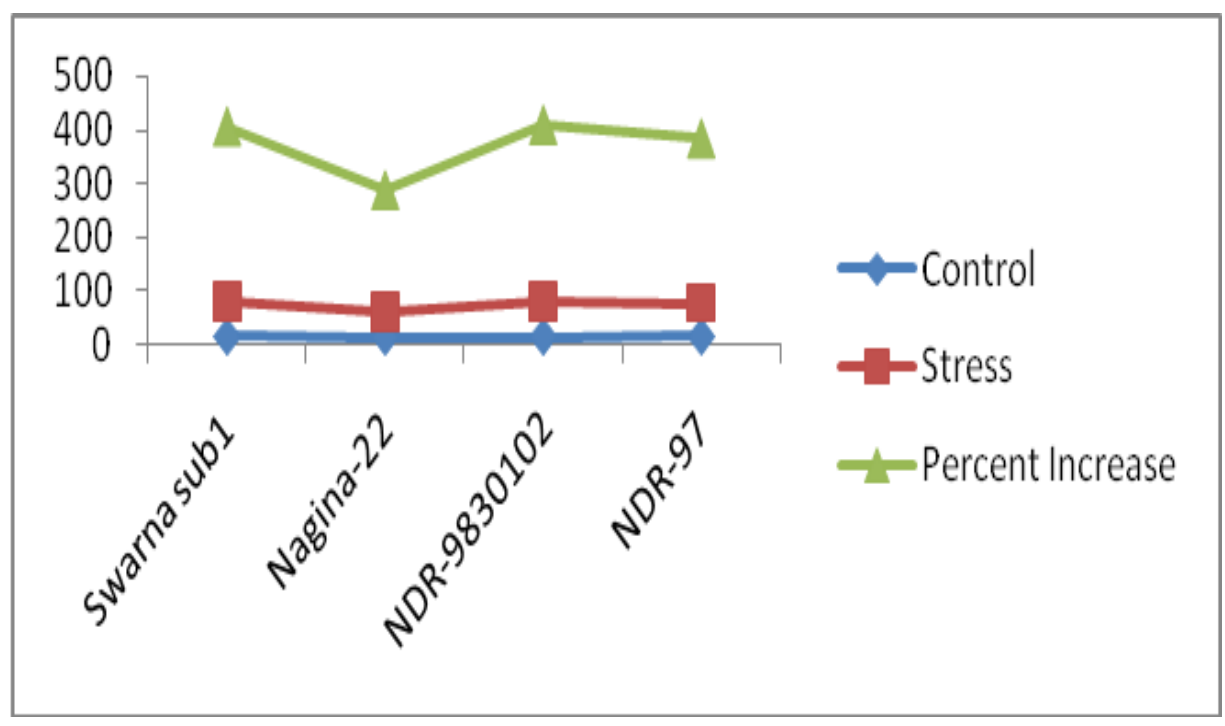


Fig.3 Effect of submergence on shoot elongation $(\mathrm{cm})$ and survival $(\%)$ in rice genotypes.

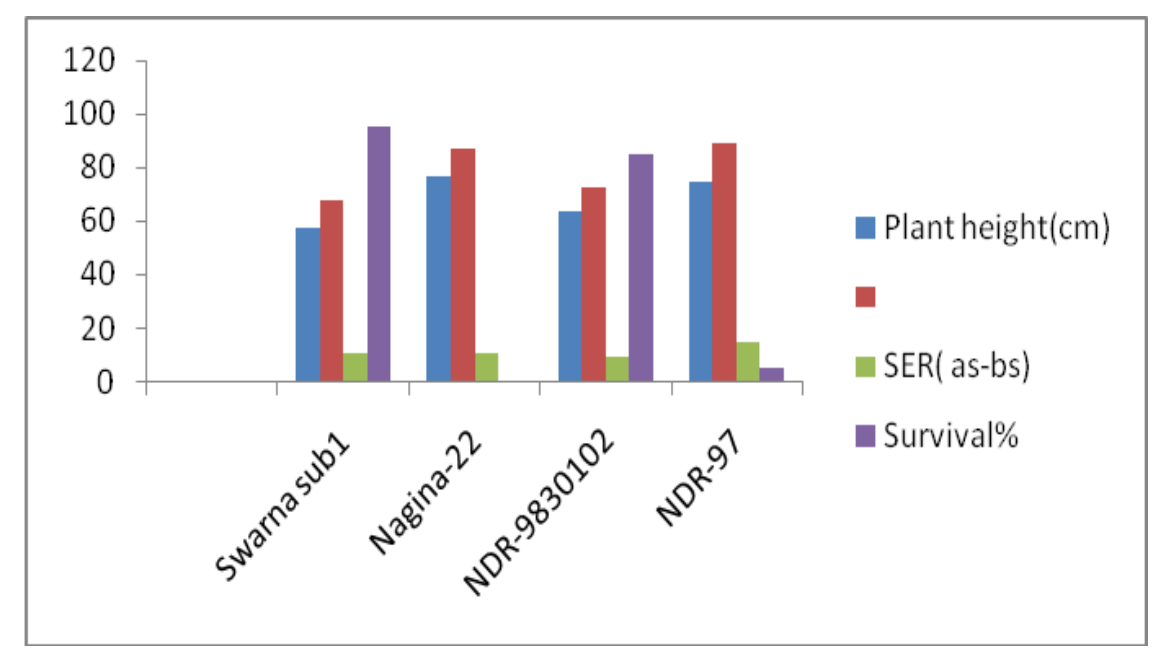

Fig.4 Effect of submergence stress on days to $50 \%$ and $100 \%$ flowering of rice genotypes

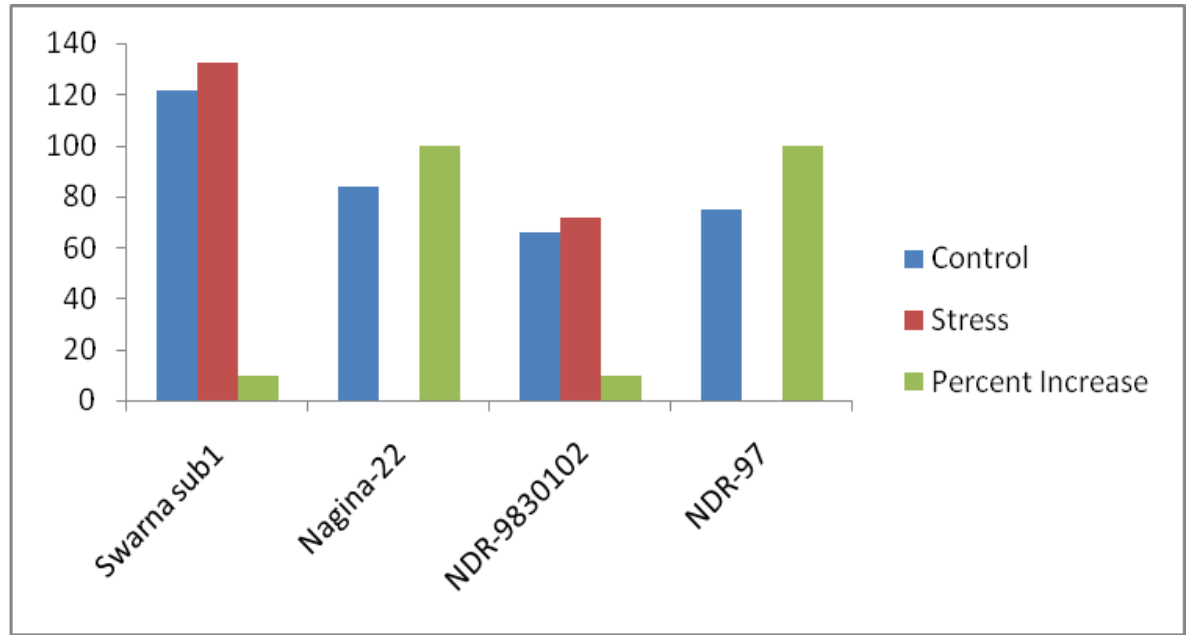

It is concluded that, Swarna Sub1 and NDR102 showed less shoot elongation high catalase and peroxidase activity and highly survived after desubmergence and also showed less reduction in yield over NDR-97. Nagina-22 could not survived after desubmergence due to high shoot elongation and less activity of catalase and peroxidase.

\section{Acknowledgement}

Authors are very thankful to Department of plant molecular biology and genetic engineering and RKVY for providing support of the experiment.

\section{References}

Ansari, R. M., Shaheen, T., Bukhari, S. A. and Husnain, T., 2015.Genetic improvement of rice for biotic and abiotic stress tolerance. Turkish J. Bot., 39:911-919.

Cox, M. C., Millenaar, F. F., Berkel, Y. E. D. J., Peeters, A. J. and Voesenek, L. A., 2003. Plant Movement. Submergence- 
Induced Petiole Elongation in Rumex palustris Depends on Hyponastic Growth. Plant Physio., 132(1), 282291.

Ella, E. S., Kawano, N., Yamauchi, Y., Tanaka, K., and Ismail, A. M., 2003. Blocking ethylene perception enhances flooding tolerance in rice seedlings. Functional Plant Biol., 30(7), 813-819.

IPCC., 2014. A Contribution of Working Group II to the Fifth Assessment Report of the Inter-governmental Panel on Climate Change. Geneva, Switzerland.

Kende, H., Van, D., Knaap, E. and Cho, H. T.,1998. Deepwater rice: a model plant to study stem elongation. Plant Physio., 118(4), 1105-1110.

Michael, B. and Phool, C., 2001. Physiology and Molecular Basis of Susceptibility
Tolerance of rice plant to complete submergence, Annals Bot., 18-35.

Reddy, M. D. and Mittra, B. N., 2013. Effects of complete plant submergence on vegetative growth, grain yield and some biochemical change in rice plants. Plant and Soil,85:365-374.

Sinha, A.K., 1972. Colorimetric assay of catalase, analytical. Biochemistry, 47: $38-4$.

Tanaka, A., Navasero, S. A., Garcia, C.V., Parao, F. T. and Ramirez, F., 1964. Growth habit of rice plant in the tropics and its effect on nitrogen response. IRRI, Tech. Bull., No. 3: 80

Verma, S., and Dubey, R. S., 2003. Lead toxicity induces lipid peroxidation and alters the activities of antioxidant enzymes in growing rice plants, Plant Sci., 164, 645-/655.

\section{How to cite this article:}

Ashish Kumar, Shambhoo Prasad, Vishwash Kumar Mishra, Rahul Kumar, Jaswant Singh, Ram Milan and Adesh Kumar. 2020. Effect of Submergence Stress on Physiological Indices and Yield of Rice (Oryza sativa L.) Genotypes. Int.J.Curr.Microbiol.App.Sci. 9(01): 994-999. doi: https://doi.org/10.20546/ijcmas.2020.901.112 